\title{
A INFLUÊNCIA DA CALCITONINA SINTÉTICA DE SALMÃO NA CICATRIZAÇÃOCUTÂNEA DE RATOS
}

\author{
INFLUENCE OF THE SYNTHETIC SALMON CALCITONIN IN CUTANEOUS WOUND \\ HEALING OF THE RATS
}

\author{
José Neiva Eulálio ${ }^{1}$; Antônio Natalino Manta Dantas ${ }^{1}$; Aristóteles Góes-Neto²; \\ Aryon de Almeida Barbosa Júnior ${ }^{3}$; André Ney Menezes Freire ${ }^{1}$
}

\begin{abstract}
RESUMO: Objetivo: O presente trabalho tem como objetivo investigar a influência da calcitonina sintética do salmão no processo cicatricial da pele da região dorsal em ratos, analisando parâmetros bioquímicos, biomecânicos e histológicos, e suas possíveis interrelações. Método: Setenta e dois (72) ratos machos adultos foram submetidos, sob anestesia geral inalatória a uma incisão linear na pele que foi, subsequientemente, suturada. Metade dos ratos (grupo teste) foi tratada no pós-operatório com calcitonina sintética do salmão, e a outra metade, sem tratamento, constituiu o grupo controle. Os animais, em pares de nove ratos cada (teste e controle), foram sacrificados no $5^{\circ}, 10^{\circ}, 15^{\circ}$ e $20^{\circ}$ dias pós-operatório para a remoção dos fragmentos de pele com cicatriz para as análises bioquímicas, biomecânicas e histológicas. Utilizou-se o teste " $\mathrm{t}$ " de Student para a comparação de médias de amostras independentes e o teste de correlação de Pearson para verificar o grau de associação entre as médias das variáveis. Resultados: A calcitonina sintética de salmão acelerou o processo cicatricial da pele, mas não de maneira linear e constante. Em comparação com os animais não-tratados, houve aumento significativo tanto do conteúdo de hidroxiprolina nas fases de proliferação inicial e tardia da cicatrização, quanto da carga máxima de ruptura na fase de proliferação tardia. Os resultados histológicos corroboram os resultados bioquímicos e biomecânicos, sugerindo uma correlação entre conteúdo de colágeno, resistência à tração e histologia da cicatriz. Conclusão: A calcitonina sintética de salmão acelerou o processo cicatricial da pele, modificando significativamente o conteúdo de colágeno e a carga máxima de ruptura, mas não de maneira linear e constante (Rev. Col. Bras. Cir. 2007; 34(4): 237-244).
\end{abstract}

Descritores: Cicatrização de feridas; Pele; Calcitonina; Hidroxiprolina; Resistência à tração.

\section{INTRODUÇÃO}

As calcitoninas apresentam ampla distribuição entre os seres vivos, sendo encontradas em diversos animais e, particularmente nos mamíferos, são produzidas nas células $\mathrm{C}$ parafoliculares, derivadas da crista neural embrionária, que se localizam na tireóide ${ }^{1}$.

A calcitonina é um peptídeo de 32 aminoácidos em cadeia simples, com uma ponte dissulfeto na porção aminoterminal e um resíduo de prolina na porção carboxiterminal. O CGRP (peptídeo relacionado ao gene da calcitonina) é um neuropeptídeo quimicamente semelhante à calcitonina, que é liberado por terminações de nervos sensoriais na derme e epiderme da pele no tecido lesado, e tem sido associado com a regeneração da pele. Ambos os peptídeos (calcitonina e CGRP) são produtos de splicing alternativo do complexo gênico da calcitonina ${ }^{2}$.

As sequiências protéicas das calcitoninas variam entre as espécies. As partes terminais da molécula são muito mais conservadas do que a parte central variável, o que pode ocasionar variações na potência e duração de ação ${ }^{3}$.

Existem calcitoninas sintéticas quimicamente semelhantes às calcitoninas nativas de mamíferos e de peixes utili- zadas para fins terapêuticos. A calcitonina sintética do salmão é a mais potente do ponto de vista farmacodinâmico, apresentando maior período de duração de ação do que as outras calcitoninas sintéticas em função da grande atividade nos receptores de ligações ${ }^{3}$.

Em doses farmacológicas a calcitonina tem um efeito direto sobre: (a) rins, aumentando a excreção de determinados íons, (b) sistema digestivo, inibindo a secreção gástrica e pancreática e aumentando a absorção de cálcio no lúmen do intestino, (c) sistema nervoso central, exercendo efeitos analgésicos e antiinflamatórios pelo aumento do aporte de cálcio, liberação de endorfinas e inibição de prostaglandinas, assim como (d) aumentando a proliferação celular para a reconstituição de tecidos lesados ${ }^{1}$.

Estudos experimentais prévios com calcitonina sintética em pele de mamíferos demonstraram o seu papel no aumento da síntese de DNA de células epiteliais e de células do tecido conectivo da pele, e proliferação de fibroblastos ${ }^{4-6}$ assim como um aumento da resistência à tração ${ }^{7}$ enquanto que o CGRP apresentou efeitos tróficos na cicatrização ${ }^{8-9} \mathrm{e}$ contração de feridas ${ }^{10}$.

Modelos de cicatrização de feridas em pele de animais de laboratório apresentam muitas características interes-

1. Professor Adjunto da Faculdade de Medicina do Departamento de Cirurgia da Universidade Federal da Bahia (UFBA).

2. Professor Titular do Departamento de Ciências Biológicas da Universidade Estadual de Feira de Santana (UEFS).

3. Pesquisador Titular do Centro de Pesquisas Gonçalo Moniz (CPqGM0.

Recebido em 02/01/2007

Aceito para publicação em 09/03/2007

Conflito de interesses: nenhum

Fonte de financiamento: nenhuma

Trabalho realizado na Faculdade de Medicina, Departamento de Cirurgia da Universidade Federal da Bahia (UFBA). 
santes que podem ser diretamente relacionadas à clínica cirúrgica, já que se tratam de feridas com perda de tecido assim como as freqüentemente encontradas na prática clínica. A lesão pode ser facilmente reproduzida da mesma forma por diferentes pesquisadores em diferentes indivíduos e a lesão pode ser continuamente observada e monitorada histologicamente através de biópsias ${ }^{11}$.

Este trabalho teve como objetivo investigar a influência da calcitonina sintética de salmão, no processo cicatricial da pele de ratos.

\section{MÉTODO}

\section{Animais}

Foram utilizados 72 ratos (Rattus novergicus), variedade albino, de linhagem Wistar, não isogênicos, machos, adultos jovens, com 17 a 20 semanas, entre 176 a 383 gramas. Os animais foram mantidos em gaiolas individuais, com água filtrada ad libitum, em uma sala climatizada $\left(23^{\circ} \mathrm{C}\right)$ sob luz artificial (12h claro / 12h escuro), e alimentados com ração comercial de manutenção para ratos ad libitum.

Os animais receberam todos os cuidados dispensados a humanos de acordo com os critérios estabelecidos no "Guide for the Care and Use of Laboratory Animals" (NIH). Este estudo foi aprovado pelo Conselho de Pesquisa do Curso de Pós-Graduação da Faculdade de Medicina da Bahia da Universidade Federal da Bahia antes do seu início.

\section{Procedimento cirúrgico}

Todos os procedimentos cirúrgicos foram realizados pela mesma equipe, com instrumentos previamente esterilizados, e todos os ratos do grupo teste (Gt) e do grupo controle (Gc) foram submetidos a um procedimento operatório padronizado.

O procedimento cirúrgico consistiu na realização de uma incisão vertical linear, medindo $5 \mathrm{~cm}$, na região dorsal do animal. Essa incisão envolveu toda espessura do tegumento, incluindo o panículo carnoso, tomando-se como referência à coluna vertebral ao longo do eixo do corpo do animal. $\mathrm{Na}$ dissecção, a ferida operatória foi divulsionada aproximadamente em $2 \mathrm{~cm}$, em ambos os lados, partindo de suas bordas, nos segmentos médios laterais até visualização da musculatura e realização da hemostasia. Após a finalização da operação procedeu-se à síntese da pele, inclusive do panículo carnoso, com sutura de pontos separados, com exposição da ferida cirúrgica.

\section{Delineamento experimental}

Após a intervenção cirúrgica, os animais foram aleatoriamente distribuidos em dois grupos, 36 dos animais constituindo o grupo teste (Gt) e 36 constituindo o grupo controle (Gc). Ambos os grupos (Gt e Gc) foram subdivididos em quatro subgrupos (Gt5/Gc5, Gt10/Gc10, Gt15/Gc15 e Gt20/Gc20), cada qual com nove animais, conforme o programa estabelecido entre a data da operação e o dia da morte $\left(5^{\circ}, 10^{\circ}, 15^{\circ}\right.$ e $20^{\circ}$ dias), quando os fragmentos de pele com cicatriz foram retirados. Os animais que morreram em alguma etapa durante o experimento não foram substituídos por outros animais.
No pós-operatório, os animais foram acondicionados em gaiolas individuais, permanecendo, ainda, em jejum por 12 horas. Eles não receberam antibióticos, e foram acompanhados diariamente, observando-se a sua atividade física, a aparência e a ingestão alimentar.

Os animais do grupo teste receberam, desde o dia da operação até o dia do sacrifício, uma aplicação da calcitonina sintética do salmão (Miacalcic®, Novartis Pharmaceulticals, Switzerland) na dose de $20 \mathrm{UI} / \mathrm{kg}$ de peso corporal, por via subcutânea, na área tricotomizada da região dorsal. A aplicação individualizada foi realizada com seringa de insulina na área tricotomizada, ao lado da incisão. As suturas de todos os animais dos grupos teste e controle foram removidas no $5^{\circ}$ dia pós-operatório.

Todos os animais do grupo teste $(\mathrm{Gt})$ e do grupo controle $(\mathrm{Gc})$ foram mortos pela inalação de vapores de éter etílico no dia determinado do pós-operatório relativo ao subgrupo a que pertenciam $\left(5^{\circ}, 10^{\circ}, 15^{\circ}\right.$ e $20^{\circ}$ dias $)$.

Um fragmento de $5 \times 5 \mathrm{~cm}^{2}$ de pele, em toda a sua espessura, incluindo a linha suturada ao centro, foi retirado de cada animal. Este fragmento foi subdividido em um fragmento de $4 \times 5 \mathrm{~cm}^{2}$ e outro de $1 \times 5 \mathrm{~cm}^{2}$. O primeiro fragmento ( 4 x $5 \mathrm{~cm}^{2}$ ) foi colocado em solução de cloreto de sódio $(\mathrm{NaCl})$ a $0,9 \%$ para a determinação da resistência da cicatriz à tração. $\mathrm{O}$ segundo foi imerso em solução neutra de formaldeído $10 \%$ (v/ v) para determinar o conteúdo de hidroxiprolina e ser utilizado para a análise histológica.

\section{Análise bioquímica}

A determinação do conteúdo de hidroxiprolina foi feita pelo método de Bergnan e Loxley ${ }^{12}$, para tecido sólido, segundo uma variante que requer a obtenção de um hidrolizado após 17 a 18 horas a $110^{\circ} \mathrm{C}$. Cada fragmento de pele foi, individualmente, submetido à hidrólise com ácido clorídrico, para a liberação da hidroxiprolina e a neutralização da acidez. A leitura da absorbância de cada amostra foi feita em espectrofotômetro (Hitachi, modelo U-2000, Japão) a 558nm, e o conteúdo de hidroxiprolina foi determinado através da comparação com uma curva padrão.

\section{Análise biomecânica}

Utilizou-se uma máquina de teste modelo 4202 (Instron, Estados Unidos), usualmente empregada para determinação das propriedades de resistência de plástico na forma de filme. Os corpos de prova foram padronizados como sendo a área seccionada medindo $4 \times 5 \mathrm{~cm}^{2}$ de comprimento. A distância entre as garras foi de $10 \mathrm{~mm}$, a velocidade da máquina foi de $5 \mathrm{~mm} / \mathrm{min}$ e a carga aplicada foi de $10 \mathrm{~kg}$. A propriedade biomecânica de carga máxima foi determinada para as amostras de todos os subgrupos teste (Gt) e controle (Gc). A variável carga máxima de ruptura foi definida como sendo o ponto de ordenada máxima representado no gráfico, formado mediante a aplicação de força de tração ao corpo de prova até a ruptura completa dos fragmentos de pele com cicatriz.

\section{Análise histológica}

Os fragmentos de pele com cicatriz foram embebidos em parafina, seccionados a 4ìm e corados em hematoxilina- 
eosina e vermelho sírio (corante específico para colágeno). As lâminas foram examinadas em microscopia óptica e o estudo histológico baseou-se na análise das características morfológicas do processo inflamatório e do grau de organização tecidual da matriz extracelular, especialmente em relação ao colágeno e fibroblastos. Os aspectos histológicos foram avaliados qualitativamente, analisando-se, por comparação, os tecidos e células presentes nas fotomicrografias dos subgrupos teste e controle ao final do $5^{\circ}, 10^{\circ}, 15^{\circ}$ e $20^{\circ}$ dias pós-operatório.

\section{Análise estatística}

Uma vez que os dados passaram no teste de normalidade, utilizou-se o teste " $t$ " de Student para amostras independentes para a comparação da diferença entre as médias das variáveis quantitativas analisadas (hidroxiprolina e carga máxima de ruptura) dos subgrupos teste e controle, quando comparados dois a dois. Para a verificação do grau de associação entre as médias do conteúdo de hidroxiprolina e carga máxima de ruptura dos fragmentos de pele com cicatriz, em cada par de subgrupos, utilizou-se o teste de correlação de Pearson. Os dados foram analisados utilizando-se o programa PAST $1.27^{13}$, e valores de $\mathrm{P} £ 0,05$ foram considerados estatisticamente significativos. Os dados foram apresentados como médias \pm desvios padrões.

\section{RESULTADOS}

Três animais morreram ao longo do período do experimento. Esses animais não foram substituídos, de modo que um total de 69 animais sobreviveu durante todo o experimento, não sendo detectada nenhuma infecção nestes animais. Nenhuma diferença na aparência, fechamento, ou crescimento de pêlos foi observada nos fragmentos de pele com cicatriz nos animais dos grupos controle e teste. Os dados quantitativos foram comparados entre os subgrupos controle e os seus subgrupos teste correspondentes, assim como entre os dias após a operação dentro de cada grupo controle e teste, como descrito a seguir.

Na Tabela 1 são apresentadas as comparações entre as médias do conteúdo de hidroxiprolina (ìmol/g) nos fragmentos de pele com cicatriz em cada par de subgrupos (Gt e Gc) por dia pós-operatório. As médias dos subgrupos teste foram superiores às dos subgrupos controle correspondentes, entretanto só foram significativamente diferentes no $5^{\circ} \mathrm{e}$ $20^{\circ}$ dias pós-operatório.

Tanto nos subgrupos teste como nos subgrupos controle o conteúdo de hidroxiprolina exibiu um padrão semelhante, um aumento rápido do $5^{\circ}$ para $10^{\circ}$ dia, alcançando os valores máximos, seguido por uma diminuição de $10^{\circ}$ para o $15^{\circ}$ dia (mais acentuado no subgrupo controle do que no subgrupo teste correspondente) e uma discreta diminuição do $15^{\circ}$ para o $20^{\circ}$ dia.

As médias de carga máxima de ruptura dos fragmentos de pele com cicatriz apresentaram valores iguais $\left(5^{\circ} \mathrm{dia}\right.$ pós-operatório) ou mais altos $\left(10^{\circ}, 15^{\circ}\right.$ e $20^{\circ}$ dias de pós-operatórios) nos subgrupos teste do que nos subgrupos controle correspondentes, porém, com significância estatística somente nos $15^{\circ}$ e nos $20^{\circ}$ dias de pós-operatório (Tabela 2).

Um padrão semelhante foi observado em ambos os subgrupos teste e controle para a carga máxima de ruptura. Houve um aumento durante o período amostrado, porém este aumento não ocorreu de maneira gradual, assemelhando-se a uma curva sinusoidal. Os valores de carga máxima de ruptura aumentaram do $5^{\circ}$ para o $10^{\circ}$ (de forma um pouco mais acentuada no subgrupo teste do que no subgrupo controle), seguido por um discreto aumento (quase um plateau) do $10^{\circ}$ para o $15^{\circ}$ dia, e um aumento muito rápido do $15^{\circ}$ para o $20^{\circ}$ dia pósoperatório (que foi mais acentuado no subgrupo teste do que no subgrupo controle).

Uma correlação significativa foi comprovada entre o conteúdo de hidroxiprolina e a carga de máxima de ruptura de fragmentos de pele com cicatriz no $10^{\circ}$ dia pós-operatório somente no grupo teste, e uma correlação significativa seme-

Tabela 1 - Comparação entre as médias do conteúdo de hidroxiprolina ( $\mu m o l / g$ ) dos fragmentos de pele com cicatriz .

\begin{tabular}{|c|c|c|c|c|c|}
\hline \multicolumn{3}{|c|}{ Subgrupos teste $(\mathbf{G t})$} & \multicolumn{3}{|c|}{ Subgrupos controle (Gc) } \\
\hline $\begin{array}{c}\text { Subgrupos } \\
\text { (dia pós-operatório) }\end{array}$ & $\begin{array}{c}\mathrm{N}^{\circ} \mathrm{de} \\
\text { unidades amostrais }\end{array}$ & Média \pm D.P. ${ }^{a}$ & $\begin{array}{c}\mathrm{N}^{\circ} \mathrm{de} \\
\text { unidades amostrais }\end{array}$ & Média \pm D.P. & $\mathrm{P}\left(\lambda^{0} \geq \lambda\right)^{\mathrm{b}}$ \\
\hline 5 & $\begin{array}{l}9 \\
(26,03 \%)^{c}\end{array}$ & $81,39 \pm 20,12$ & 8 & $64,57 \pm 9,73$ & $0,04^{*}$ \\
\hline 10 & $\begin{array}{l}9 \\
(2,98 \%)^{\mathrm{c}}\end{array}$ & $106,55 \pm 17,73$ & 9 & $103,46 \pm 14,92$ & 0,69 \\
\hline 15 & $\begin{array}{c}9 \\
(23,16 \%)^{\mathrm{c}}\end{array}$ & $101,42 \pm 27,60$ & 9 & $82,35 \pm 26,13$ & 0,15 \\
\hline 20 & $\begin{array}{l}8 \\
(16,71 \%)^{c}\end{array}$ & $92,35 \pm 12,30$ & 8 & $79,13 \pm 9,29$ & $0,02^{*}$ \\
\hline
\end{tabular}

${ }^{a}$ D.P. = desvio padrão

${ }^{b}$ Probabilidade obtida a partir da aplicação do teste " $t$ ” de Student (duas amostras independentes). Critério do teste ( $\lambda$ ): média das amostras. Nivel de significância de 5\% $(\alpha=0,05)$

${ }^{c}$ Percentual de aumento no subgrupo tratado com calcitonina em relação ao subgrupo controle

* Significativo para $\alpha=0,05(5 \%)$ 
Tabela 2 - Comparação entre as médias de carga máxima de ruptura (kgf) dos fragmentos de pele com cicatriz.

\begin{tabular}{|c|c|c|c|c|c|}
\hline \multicolumn{3}{|c|}{ Subgrupos teste $(\mathrm{Gt})$} & \multicolumn{3}{|c|}{ Subgrupos controle $(\mathbf{G c})$} \\
\hline $\begin{array}{c}\text { Subgrupos } \\
\text { (dia pós-operatório) }\end{array}$ & $\begin{array}{c}\mathrm{N}^{\mathrm{o}} \text { de } \\
\text { unidades amostrais }\end{array}$ & Média \pm D.P. ${ }^{a}$ & $\begin{array}{c}\mathrm{N}^{\mathbf{o}} \text { de } \\
\text { unidades amostrais }\end{array}$ & Média \pm D.P. & $\mathrm{P}\left(\lambda^{\mathrm{o}} \geq \lambda\right)^{\mathrm{b}}$ \\
\hline 5 & 9 & $\begin{array}{l}0,24 \pm 0,20 \\
(0 \%)\end{array}$ & 7 & $0,24 \pm 0,10$ & 0,95 \\
\hline 10 & 9 & $\begin{array}{l}1,13 \pm 0,47 \\
(15,11 \%)\end{array}$ & 7 & $0,98 \pm 0,19$ & 0,44 \\
\hline 15 & 9 & $\begin{array}{l}1,39 \pm 0,34 \\
(36,06 \%)\end{array}$ & 9 & $1,02 \pm 0,36$ & $0,04 *$ \\
\hline 20 & 8 & $\begin{array}{l}4,30 \pm 1,64 \\
(71,53 \%)\end{array}$ & 8 & $2,51 \pm 0,64$ & $0,01 *$ \\
\hline
\end{tabular}

${ }^{a}$ D.P. = desvio padrão

${ }^{b}$ Teste " $t$ " de Student (duas amostras independentes). Critério do teste ( $\lambda$ ): média das amostras. Nível de significância de 5\% ( $\left.\alpha=0,05\right)$

"Percentual de aumento no subgrupo tratado com calcitonina em relação ao subgrupo controle

* Significativo para $\alpha=0,05(5 \%)$

lhante foi encontrada no $20^{\circ}$ dia pós-operatório em ambos os grupos, teste e controle (Tabela 3).

Nas figuras 1-8 são apresentados os resultados histológicos. No $5^{\circ}$ dia pós-operatório, inflamação crônica moderada, estendendo-se ao músculo e ao subcutâneo com presença de tecido de granulação ocorreu no subgrupo controle (Figura 1), enquanto que, no subgrupo teste correspondente, observou-se uma proliferação de fibroblastos com fibrose moderada, estendendo-se até o subcutâneo (Figura 2)

No $10^{\circ}$ dia pós-operatório no subgrupo controle, o corte transversal histológico foi caracterizado por hiperplasia epitelial, proliferação de fibroblastos e cicatriz fibrótica (Figura 3) enquanto que, o subgrupo teste correspondente, apresentou proliferação de fibroblastos com fibrose subepidérmica focal (Figura 4).

No $15^{\circ}$ dia pós-operatório no subgrupo controle, a seção foi caracterizada pela proliferação subepidérmica de fibroblastos com fibrose recente, (Figura 5), enquanto que, no subgrupo teste correspondente, ocorreu fibrose subepidérmica focal e proliferação acentuada de fibroblastos (Figura 6).

No $20^{\circ}$ dia pós-operatório, no subgrupo de controle, a seção apresentou proliferação de fibroblastos com cicatriz dérmica (Figura 7), enquanto que, o subgrupo experimental correspondente, mostrou cicatriz extensa, fibrose subepidérmica com proliferação acentuada de fibroblastos (Figura 8).

\section{DISCUSSÃO}

A cicatrização de feridas é uma cascata complexa de eventos, iniciada por lesão tecidual, para a restauração da integridade de um tecido e envolve ativação coordenada, divisão, quimiotaxia, migração e diferenciação celular ${ }^{14}$.

Todo o processo pode ser dividido em fases distintas, caracterizadas pela população celular predominante e segue uma seqüência conservada de eventos que se sobrepõem no tempo e incluem inflamação, proliferação e remodelação tecidual $^{15}$.

Todas as fases da cicatrização são direta ou indiretamente mediadas por citocinas liberadas localmente, fatores de crescimento e hormônios. $\mathrm{O}$ tecido de granulação começa a invadir o espaço da ferida aproximadamente quatro dias após a lesão, com fibroblastos produzindo a nova matriz extracelular necessária ao desenvolvimento de células e vasos sangüíneos que levam o oxigênio e nutrientes necessários à sustentação do metabolismo celular ${ }^{14,15}$.

Tabela 3 - Correlação entre as médias do conteúdo de hidroxiprolina (ìmol/g) e as médias de carga máxima de ruptura (kgf) dos fragmentos de pele com cicatriz.

\begin{tabular}{|c|c|c|}
\hline \multirow[t]{2}{*}{ Dia pós-operatório } & \multicolumn{2}{|c|}{$\mathbf{r}^{\mathrm{a}} / \mathbf{P}^{\mathrm{b}}$} \\
\hline & Subgrupos teste (Gt) & Subgrupos controle (Gc) \\
\hline 5 & $0,40 / \quad 0,27$ & $0,64 / \quad 0,06$ \\
\hline 10 & $0,67 / 0,04^{*}$ & $0,17 / \quad 0,64$ \\
\hline 15 & $0,34 / \quad 0,36$ & $0,10 / \quad 0,79$ \\
\hline 20 & $0,74 / \quad 0,02 *$ & $0,79 / \quad 0,009^{*}$ \\
\hline
\end{tabular}

${ }^{a}$ Coeficiente de correlação de Pearson

${ }^{b}$ Probabilidade das variáveis não serem correlacionadas

* Significativo para $\alpha=0,05(5 \%)$ 


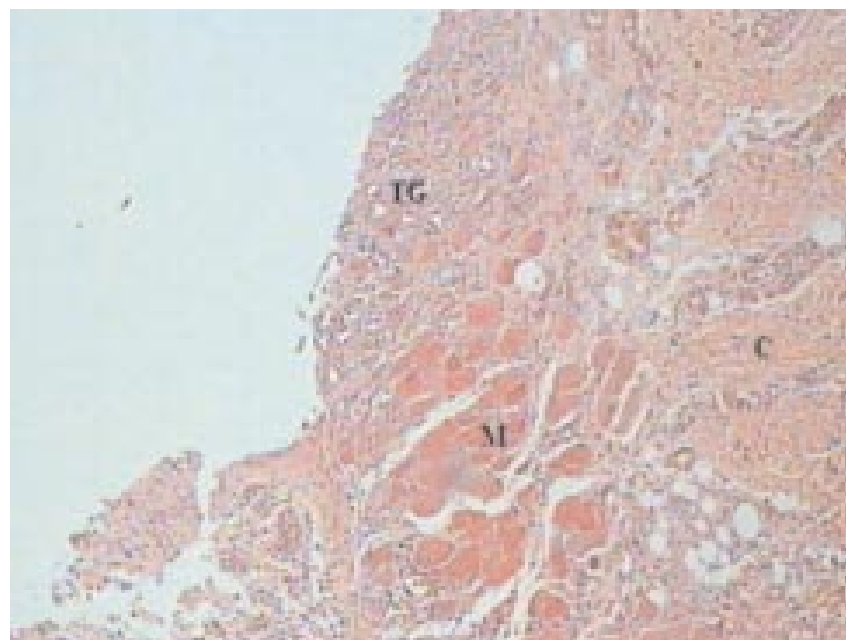

Figura 1 - Fotomicrografia de tecido cicatricial de um animal do subgrupo controle no $5^{o}$ dia pós-operatório. Hematoxilina-eosina, X10. (TG: Tecido de granulação; C: colágeno; M: músculo). 54 x 40 $m m(300 \times 300 \mathrm{DPI})$.

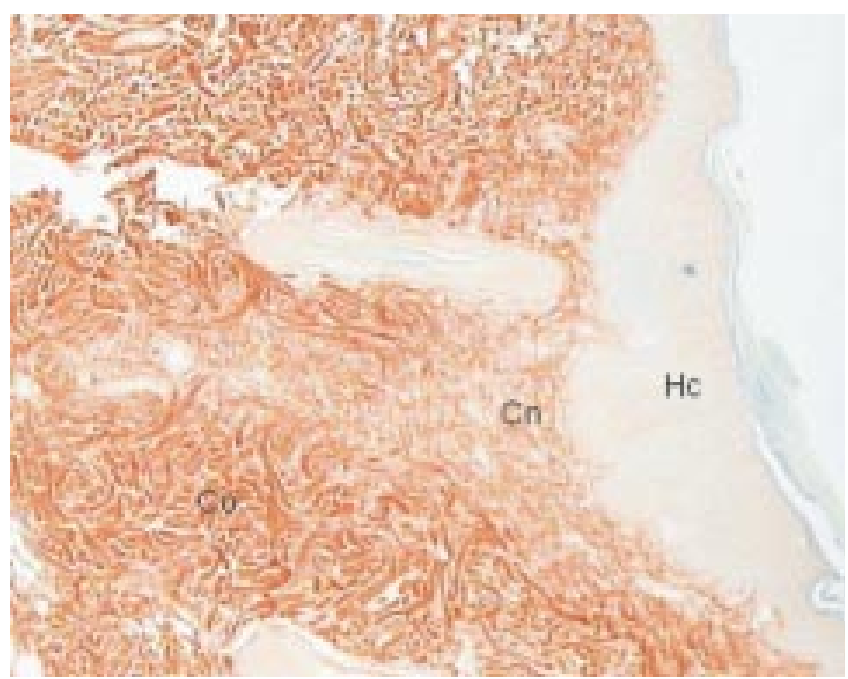

Figura 3 - Fotomicrografia de tecido cicatricial de um animal do subgrupo controle no $10^{\circ}$ dia pós-operatório. Vermelho sírio, X10. (Cn: colágeno novo; Co: colágeno antigo Hc: hiperceratose). $54 x$ $40 \mathrm{~mm}(300 \times 300 \mathrm{DPI})$.

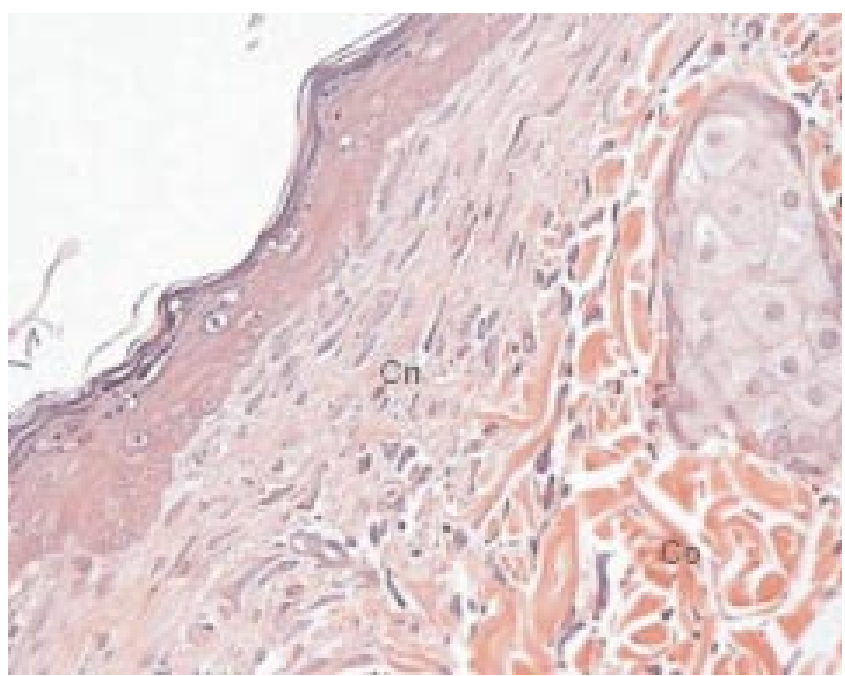

Figura 5 - Fotomicrografia de tecido cicatricial de um animal do subgrupo controle no $15^{\circ}$ dia pós-operatório. Hematoxilina-eosina, X40. (Cn: colágeno novo; Co: colágeno antigo). $54 \times 40 \mathrm{~mm}$ (300 x $300 \mathrm{DPI})$.

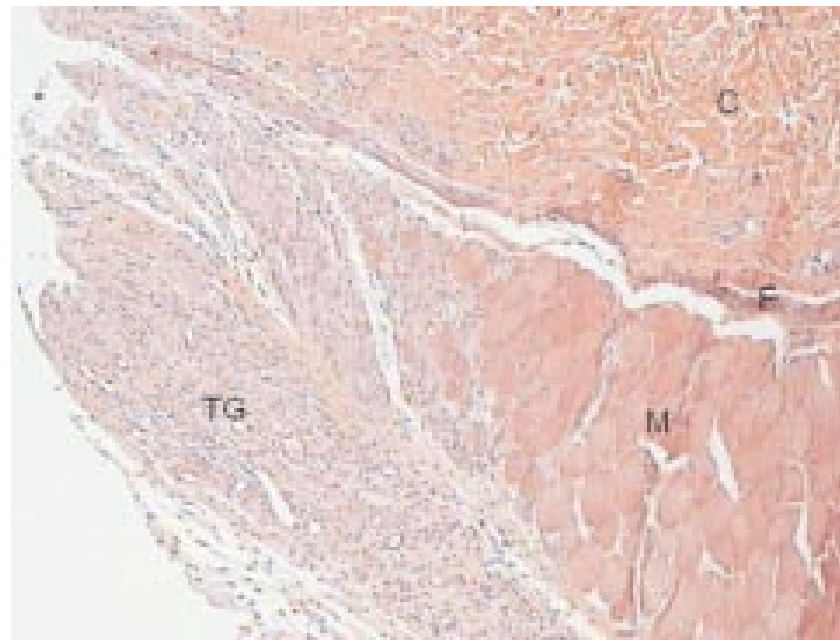

Figura 2 - Fotomicrografia de tecido cicatricial de um animal do subgrupo teste no $5^{\circ}$ dia pós-operatório. Hematoxilina-eosina, X10. (TG: Tecido de granulação; C: colágeno; M: músculo; F: fibrose). $54 \times 40 \mathrm{~mm}(300 \times 300 \mathrm{DPI})$.

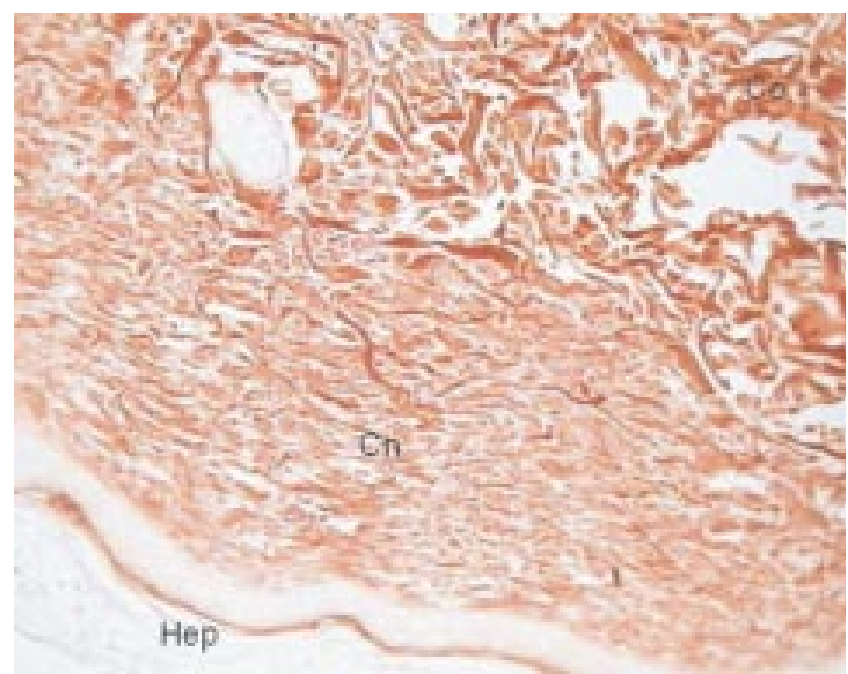

Figura 4 - Fotomicrografia de tecido cicatricial de um animal do subgrupo teste no $10^{\circ}$ dia pós-operatório. Vermelho sírio, X20. (Cn: colágeno novo; Co: colágeno antigo Hep: hipertrofia epitelial). $54 x$ $40 \mathrm{~mm}(300 \times 300 \mathrm{DPI})$.

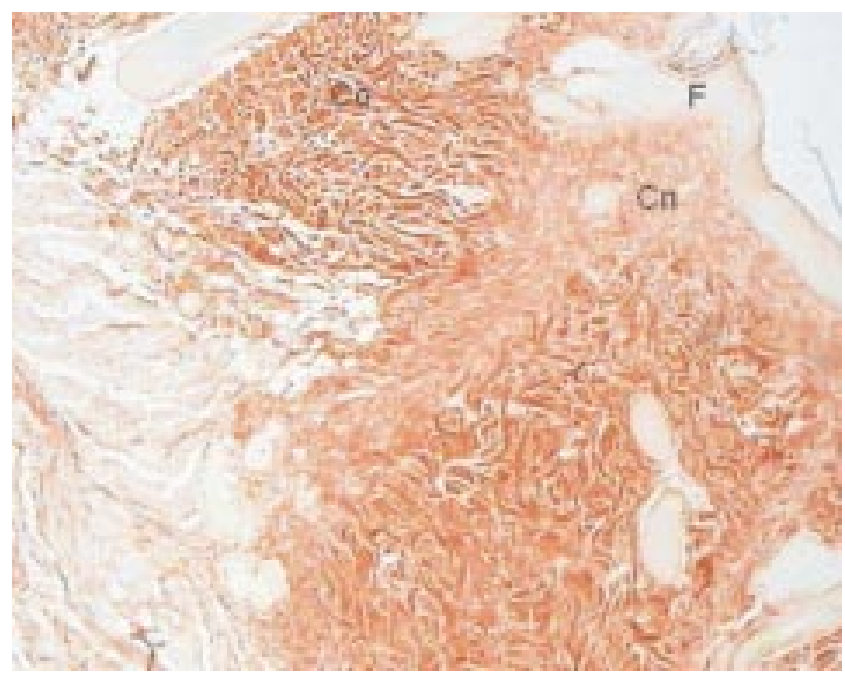

Figura 6 - Fotomicrografia de tecido cicatricial de um animal do subgrupo teste no $15^{\circ}$ dia pós-operatório. Vermelho sírio, X40. (Cn: colágeno novo; Co: colágeno antigo; F: fibrose). $54 \times 40 \mathrm{~mm}(300 \times 300 \mathrm{DPI})$. 


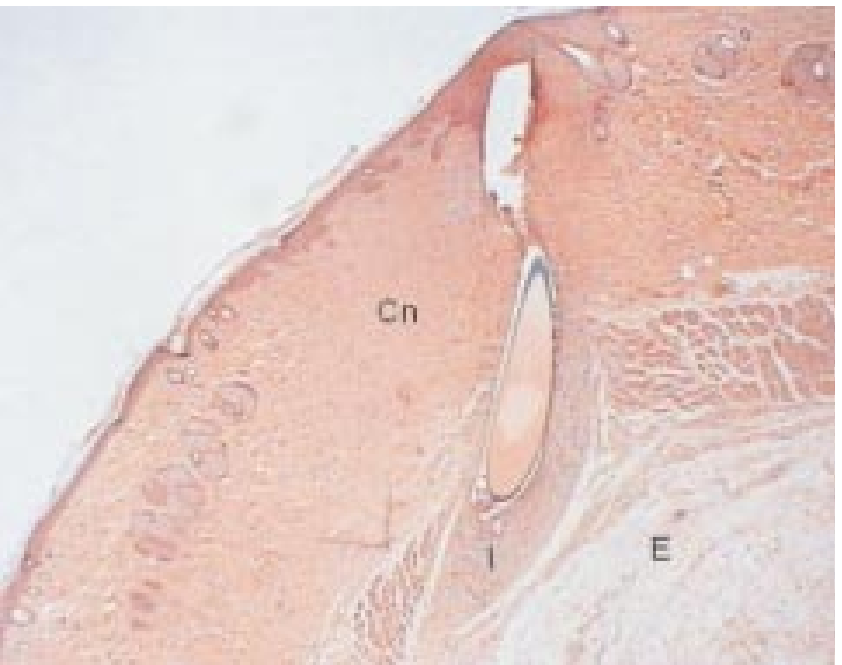

Figura 7 - Fotomicrografia de tecido cicatricial de um animal do subgrupo controle no $20^{\circ}$ dia pós-operatório. Hematoxilina-eosina, X4. (Cn: colágeno novo; I: inflamação crônica; E: edema). $54 \times 40$ $m m(300 \times 300 \mathrm{DPI})$.

No presente estudo, no $5^{\circ}$ dia pós-operatório, os resultados histológicos de animais tratados com calcitonina (Figura 2) foram qualitativamente distintos daqueles encontrados no subgrupo controle correspondente (Figura 1), uma vez que houve uma proliferação de fibroblastos muito maior, assim como a presença de fibrose moderada, similarmente ao encontrado em estudos prévios que demonstraram um aumento da proliferação de fibroblastos tanto in vitro (cultura de células) como in vivo (tecido cicatricial) depois da administração de calcitonina, quando injeções de calcitonina induziram a um grande aumento nos níveis de cálcio, ocorrendo uma melhora significativa do processo cicatricial em coelhos $\mathrm{s}^{4,5}$. Trabalhos que utilizaram fibroblastos em cultura identificaram a capacidade do cálcio local na modulação da proliferação celular, motilidade e maturação, sugerindo que a modulação de cálcio é essencial no processo cicatricial ${ }^{16}$.

Este resultado histológico qualitativamente distinto corrobora a diferença significativa do conteúdo de hidroxiprolina ( $p<0.05$ ) em fragmentos de tecido com cicatriz entre os animais tratados e não-tratados com calcitonina no $5^{\circ}$ dia pós-operatório (Tabela 1). Este aumento de produção de colágeno pode estar relacionado a uma maior proliferação de fibroblastos em animais tratados com calcitonina assim como também observado para outros mediadores de cicatrização, como alguns fatores de crescimento ${ }^{17}$.

As seções histológicas dos subgrupos teste e controle nos $10^{\circ}$ e $15^{\circ}$ dias pós-operatórios (Figuras 5-8) foram qualitativamente semelhantes como também nenhuma diferença estatisticamente significativa do conteúdo de hidroxiprolina foi observada entre animais tratados e não-tratados com calcitonina nesse período, embora o conteúdo de hidroxiprolina dos subgrupos teste sempre tenha sido mais alto do que os dos subgrupos controle correspondentes (Tabela 1).

No $20^{\circ}$ dia pós-operatório, porém, as secções histológicas do subgrupo teste (Figura 8) foram consideravelmente diferentes daquelas do subgrupo controle correspon-

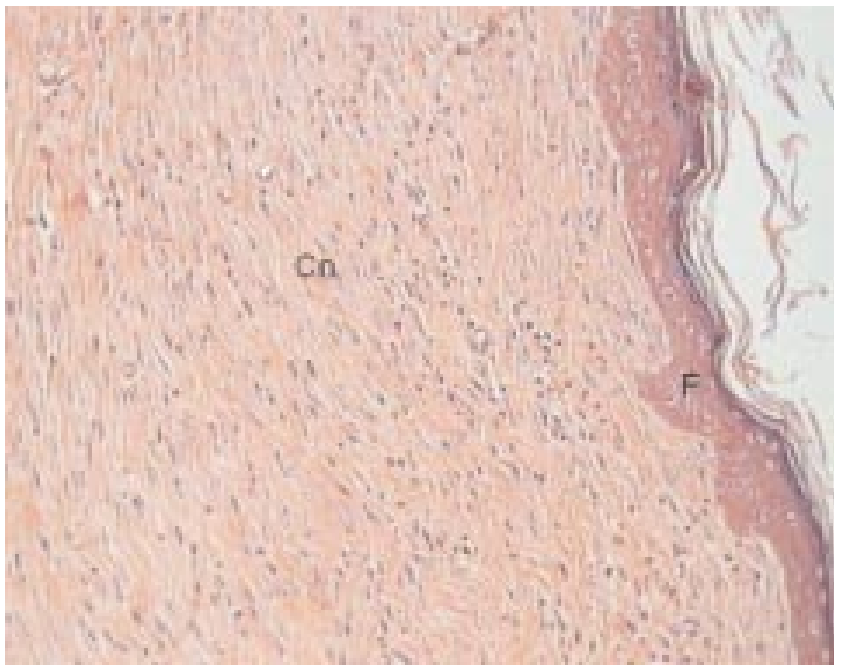

Figura 8 - Fotomicrografia de tecido cicatricial de um animal do subgrupo teste no $20^{\circ}$ dia pós-operatório. Hematoxilina-eosina, X20. (Cn: colágeno novo com cicatriz; F: fibrose). $54 \times 40 \mathrm{~mm}(300 \times 300$ $D P I)$.

dente (Figura 6), já que esses animais tratados com calcitonina apresentaram uma maior proliferação de fibroblastos com fibrose acentuada e, similarmente ao que foi observado no $5^{\circ}$ dia pós-operatório, houve diferença no conteúdo de hidroxiprolina $(\mathrm{p}<0.05)$ entre animais tratados e não tratados com calcitonina (Tabela 1). Este resultado sugere que, até mesmo ao final da fase de proliferação e início de fase de remodelação do processo cicatricial, a calcitonina pode estar envolvida com a proliferação de fibroblastos e, por conseguinte, com a produção de colágeno, através da modulação do metabolismo de cálcio local.

Após migrarem para o tecido lesado, os fibroblastos iniciam a síntese de uma matriz extracelular provisória que é subseqüentemente substituída por uma matriz de colágeno. Colágenos são as principais macromoléculas da maioria dos tecidos conjuntivos e as proteínas mais abundantes do corpo humano, e a pele é particularmente rica em colágenos. As fibrilas de colágeno, que se agregam para formar as fibras de colágeno, são insolúveis, altamente resistentes à tração, e efetivamente contribuem para o processo curativo pela reconstituição de tecidos lesados e conferindo resistência à tração em cicatrizes $^{18}$.

No presente estudo, o conteúdo total de colágeno (indiretamente medido através de conteúdo de hidroxiprolina) do fragmento de pele com cicatriz, após alcançar um pico máximo por volta do $10^{\circ}$ dia pós-operatório, começou a diminuir, enquanto que a resistência à tração aumentou, provavelmente como resultado da modificação estrutural do colágeno recentemente depositado, com a maturação das fibrilas de colágeno desorganizadas em fibras compactas.

Os fragmentos de pele com cicatriz de animais tratados com calcitonina apresentaram valores significativamente mais altos de carga máxima de ruptura do que os encontrados nos animais não tratados, mas apenas nos $15^{\circ}$ e $20^{\circ}$ dias pós-operatórios, ou seja, somente após a diminuição do conteúdo de colágeno. Garcia $e t a l .^{7}$ também observaram uma 
resistência à tração significativamente mais elevada em fragmentos de pele com cicatriz de animais tratados com calcitonina, mas já, a partir do $5^{\circ}$ dia pós-operatório, seguido por um aumento não significativo no $8^{\circ}$ dia, e então, novamente, um aumento significativo nos $10^{\circ}$ e $15^{\circ}$ dias de pósoperatórios. $\mathrm{O}$ aumento em diâmetro da fibra do colágeno é geralmente associado com um aumento em resistência à tração da cicatriz, e as ligações cruzadas das fibrilas de colágeno são largamente responsáveis por estas mudanças morfológicas e o aumento da resistência da cicatriz. A resistência à tração não depende somente da quantidade absoluta de fibras de colágeno presentes, mas, principalmente da quantidade de ligações covalentes intermoleculares (pontes cruzadas) ${ }^{19}$.

Em comparação aos animais não tratados, um aumento estatisticamente significativo da hidroxiprolina, e conseqüentemente, do conteúdo de colágeno, foi observado na fase inicial e tardia de proliferação/inicial de remodelação da cicatrização, como também um aumento estatisticamente significativo da carga máxima de ruptura na fase tardia de proliferação/inicial de remodelação. Além disto, os resultados histológicos foram congruentes com os resultados bioquímicos e biomecânicos, corroborando-os.
Os resultados do presente estudo indicam que administração local de calcitonina sintética de salmão melhorou o processo cicatricial de feridas incisionais na pele da região dorsal de ratos, mas não de uma maneira linear constante.

Estudos a longo prazo envolvendo todo o período de um típico processo cicatricial (80-100 dias), devem ser realizados para uma melhor análise dos efeitos múltiplos da calcitonina na cicatrização, como também da sua atividade antimicrobiana, que ainda permanece subestimada ${ }^{20}$.

\section{AGRADECIMENTOS}

Gostaríamos de agradecer a todas as pessoas que contribuíram direta ou indiretamente para a execução deste trabalho: Prof. Dra. Maria da Graça Faria Pinto e toda a equipe do Biotério Central da Universidade Federal da Bahia (UFBA); Prof. Dra. Carmem Célia Carvalho Smith, Prof. Dra. Roseana Dantas Mazza e toda a equipe do Laboratório de Nutrição Experimental (UFBA); Dra. Luciana de Menezes Silva, e toda a equipe do Centro de Pesquisa Gonçalo Muniz da Fundação Oswaldo Cruz. Este trabalho é resultado da Tese de Doutorado do Dr. José Neiva Eulálio.

\begin{abstract}
Background: The aim of the present study was to investigate the influence of synthetic salmon calcitonin on wound healing in dorsal skin of rats. Biochemical, biomechanical, and histological parameters were analyzed as well as possible relationships between them. Methods: Seventy-two male rats were randomly assigned to control and experimental groups. Surgical procedure comprised the creation of incisional cutaneous wound, which was subsequently sutured. Experimental group was treated with synthetic salmon calcitonin postoperatively. The animals were sacrificed in the $5^{\text {th }}, 10^{\text {th }}, 15^{\text {th }}$ and $20^{\text {th }}$ postoperative days for wounded skin specimens removal for biochemical, biomechanical, and histological studies. Results: In comparison to nontreated animals, a significant increase in hydroxyproline and collagen contents was observed in early and late proliferation phases of wound healing. Additionally, a significant increase in maximum rupture load in the late proliferation phase was observed. Histological findings corroborated biochemical and biomechanical results. Conclusion: Synthetic salmon calcitonin improved the wound healing process, but not in a linear constant fashion.
\end{abstract}

Key words: Wound healing; Skin; Calcitonin; Hydroxyproline; Tensile strength.

\section{REFERÊNCIAS}

1. Inzerillo AM, Zaidi M, Huang CL. Calcitonin: physiological actions and clinical applications. J Pediatr Endocrinol Metab. 2004; 17(7):931-40.

2. Huang CL, Sun L, Moonga BS, Zaidi M. Molecular physiology and pharmacology of calcitonin. Cell Mol Biol (Noisy-le-grand). 2006; 52(3):33-43.

3. Zaidi M, Inzerillo AM, Moonga BS, Bevis PJ, Huang CL. Forty years of calcitonin -- where are we now? A Tribute to the work of Iain Macintyre, FRS. Bone. 2002; 30(5):655-63.

4. Lupulescu A. Effect of calcitonin on DNA synthesis in experimental wounds. Proc Soc Exp Biol Med. 1975; 150(3):703-6.

5. Lupulesco A, Habowsky J. Effects of calcitonin on wound healing: a morphological study in rabbits. J Surg Res. 1978; 25(3):260-8.

6. Khomullo GV, Ivanenko TV, Lotova VI. [DNA synthesis in connective tissue elements of regenerating skin under the influence of thyrocalcitonin and hypoxia]. Biull Eksp Biol Med. 1977; 84(11):618-21.
7. García García J, Rodriguez Rodriguez JM, Almazan Enriquez A, Gomez Alonso A. Effects of pharmacological doses of synthetic salmon calcitonin in wound healing in rats. Int Surg.1985; 70(3):243-5.

8. Wallengren J, Chen D. Local skin lesions in the rat after subcutaneous deposition of capsaicin. Skin Pharmacol Appl Skin Physiol. 2002; 15(3):154-65.

9. Richards AM, Floyd DC, Terenghi G, McGrouther DA. Cellular changes in denervated tissue during wound healing in a rat model. Br J Dermatol. 1999; 140(6):1093-9.

10. Engin C. Effects of calcitonin gene-related peptide on wound contraction in denervated and normal rat skin: a preliminary report. Plast Reconstr Surg. 1998; 101(7):1887-90.

11. Gottrup F, Ågren MS, Karlsmark T. Models for use in wound healing research: a survey focusing on in vitro and in vivo adult soft tissue. Wound Repair Regen. 2000; 8(2):83-96.

12. Bergman I, Loxley R. Two improved and simplified methods for the spectrophotometric determination of hydroxyproline. Ann Chem. 1963; 35:1961-5. 
13. Hammer $\varnothing$, Harper DAT, Ryan PD. PAST: Paleontological Statistics Software Package for Education and Data Analysis. Palaeontologia Electronica. 2001; 4(1): 1-9.

14. Singer AJ, Clark RAF. Cutaneous wound healing. N Engl J Med. 1999; 341(10):738-46.

15. Clark RAF. Wound repair: overview and general considerations. In: Clark RAF, editor. The molecular and cellular biology of wound repair. New York: Plenum Press; 1996. p. 3-50.

16. Lansdown ABG. Calcium: a potential central regulator in wound healing in the skin. Wound Repair Regen. 2002; 10(5):271-85

17. Laato M, Kähäri VM, Niinikoski J, Vuorio E. Epidermal growth factor increases collagen production in granulation tissue by stimulation of fibroblast proliferation and not by activation of procollagen genes. Biochem J. 1987; 247(2):385-8.

18. Myllyharju J, Kivirikko KI. Collagens and collagen-related diseases. Ann Med. 2001; 33(1):7-21.
19. Bailey AJ, Bazin S, Sims TJ, Le Lous M, Nicoletis C, Delaunay A. Characterization of the collagen of human hypertrophic and normal scars. Biochim Biophys Acta. 1975; 405(2):412-21.

20. Gallo RL, Huttner KM. Antimicrobial peptides: an emerging concept in cutaneous biology. J Invest Dermatol. 1998; 111(5):739-43.

Como citar este artigo:

Eulálio JN, Dantas ANM, Góes-Neto A, Barbosa Júnior AA, Freire ANM. A influência da calcitonina sintética de salmão na cicatrização cutânea de ratos. Rev Col Bras Cir. 2007; 34(4). Disponível em URL: www.scielo.br/rcbc

Endereço para correspondência:

José Neiva Eulálio

Rua Plínio Moscoso, 956

Jardim Apipema

40155-810 - Salvador - BA

E-mail:jneivaeulalio@yahoo.com.br 